\title{
Seismic response trends evaluation via long term monitoring and finite element model updating of an RC building including soil-structure interaction
}

\author{
F. Butt, P. Omenzetter \\ Department of Civil \& Environmental Engineering, The University of Auckland, Private Bag 92019, \\ Auckland 1142, New Zealand
}

\begin{abstract}
This paper presents a study on the seismic response trends evaluation and finite element model updating of a reinforced concrete building monitored for a period of more than two years. The three storey reinforced concrete building is instrumented with five tri-axial accelerometers and a free-field tri-axial accelerometer. The time domain N4SID system identification technique was used to obtain the frequencies and damping ratios considering flexible base models taking into account the soil-structure-interaction (SSI) using 50 earthquakes. Trends of variation of seismic response were developed by correlating the peak response acceleration at the roof level with identified frequencies and damping ratios. A general trend of decreasing frequencies was observed with increased level of shaking. To simulate the behavior of the building, a three dimensional finite element model (FEM) was developed. To incorporate real in-situ conditions, soil underneath the foundation and around the building was modeled using spring elements and non-structural components (claddings and partitions) were also included. The developed FEM was then calibrated using a sensitivity based model updating technique taking into account soil flexibility and non-structural components as updating parameters. It was concluded from the investigation that knowledge of the variation of seismic response of buildings is necessary to better understand their behavior during earthquakes, and also that the participation of soil and non-structural components is significant towards the seismic response of the building and these should be considered in models to simulate the real behavior.
\end{abstract}

Keywords: Structural health monitoring, seismic response, system identification, model updating, soil-structureinteraction

\section{INTRODUCTION}

The full scale, in-situ investigations of instrumented buildings present an excellent opportunity to observe their dynamic response in as-built environment, which includes all the real physical properties of a structure under study and its environment. Previous studies have shown that the dynamic characteristics tend to vary with vibration amplitude ${ }^{1-3}$. It is, therefore, important to see the behavior of buildings under different excitation scenarios. The trends of variation of dynamic characteristics, including modal frequencies and damping ratios, thus developed will provide quantitative data for the variations in the behavior of buildings. Moreover, such studies will provide invaluable information for the development and calibration of realistic models for the prediction of seismic response of structures in model updating and structural health monitoring studies ${ }^{4,5}$. An important factor in the modeling of civil engineering structures is the effect of soil-structure-interaction. Soil-structure-interaction involves transfer of energy from the ground to the structure and back to the ground ${ }^{6}$. Due to the flexibility of soil, the natural period can be longer than the period of the fixed base building. Building period is a very important parameter in the design and analysis of earthquake resistant structures. Proper modeling of soil-structure-interaction is, therefore, necessary to better predict the actual response of structures.

This study comprises two parts. In the first part, seismic response trends of an instrumented RC building under 50 earthquakes were evaluated. For this purpose, relationships between natural frequencies and damping ratios with peak response acceleration (PRA) at the roof were statically examined. Natural frequencies and damping ratios, accounting for SSI, were identified using the state-of-the-art N4SID system identification technique. For natural input modal analysis, this technique is considered to belong to the most powerful class of the known system identification techniques in the

*p.omenzetter@auckland.ac.nz; phone 649373 7599-88138; fax 64 9 373-7462; www.auckland.ac.nz 
Return to your MySPIE To Do List at http://myspie.org and approve or disapprove this submission. Your manuscript will not be published without this approval. Please contact author_help@spie.org with any questions or concerns.

time domain ${ }^{7}$. The contribution of this study is that all the aforementioned relationships are obtained via rigorous statistical analyses using a relatively large number of seismic events, which is still rather rare in the existing literature.

The second part of this study comprises the development and updating of a finite element model (FEM) of the building incorporating the soil flexibility and non-structural components (NSCs). The FEM is updated using a sensitivity based technique using the dynamic properties of the building identified during the earthquake that produced the largest recorded response. The study attempts to highlight the importance of modeling the soil and NSCs to simulate the real behavior of the structures. The outcome of the two aforementioned studies is expected to further the understanding of dynamic behavior of buildings during earthquakes and provide new quantitative data for studying seismic responses of as-built structures, structural health monitoring and model updating.

\section{DESCRIPTION OF THE BUILDING AND INSTRUMENTATION}

The building under study is situated at Lower Hutt approximately $20 \mathrm{~km}$ north-east of Wellington, New Zealand. It is a three storey RC structure with a basement, $44 \mathrm{~m}$ long, $12.19 \mathrm{~m}$ wide and $13.4 \mathrm{~m}$ high (measured from the base level). The structural system consists of 12 beam-column frames and a $2.54 \times 1.95 \mathrm{~m}$ RC shear core with the wall thickness of $229 \mathrm{~mm}$, which houses an elevator. The plan of the building is rectangular but additional beams along the longitudinal direction inside the perimeter beams and the shear core make it unsymmetrical in terms of stiffness distribution (Figure 1a). The exterior beams are $762 \times 356 \mathrm{~mm}$ except at the roof level where these are $1067 \times 356 \mathrm{~mm}$. All the interior beams and all the columns are $610 \times 610 \mathrm{~mm}$. Floors are $127 \mathrm{~mm}$ thick reinforced concrete slabs except a small portion of the ground floor near the stairs where it is $203 \mathrm{~mm}$ thick. The roof comprises corrugated steel sheets over timber planks supported by steel trusses. The building is resting on separate pad type footings of base dimensions $2.29 \times 2.29 \mathrm{~m}$ at the perimeter and $2.74 \times 2.74 \mathrm{~m}$ inside the perimeter and $610 \times 356 \mathrm{~mm}$ tie beams are provided to join all the footings together.

This building is instrumented with five tri-axial accelerometers. Two accelerometers are fixed at the base level, one underneath the first floor slab, and two at the roof level as shown in Figure 1b. There is also a free field tri-axial accelerometer mounted at the ground surface and located $39.4 \mathrm{~m}$ from the south end of the building. Figure 1 also shows the common global axes $\mathrm{x}$ and $\mathrm{y}$ used for identifying directions in the subsequent discussions. All the data is stored to a central recording unit and is available online (www.geonet.org.nz).
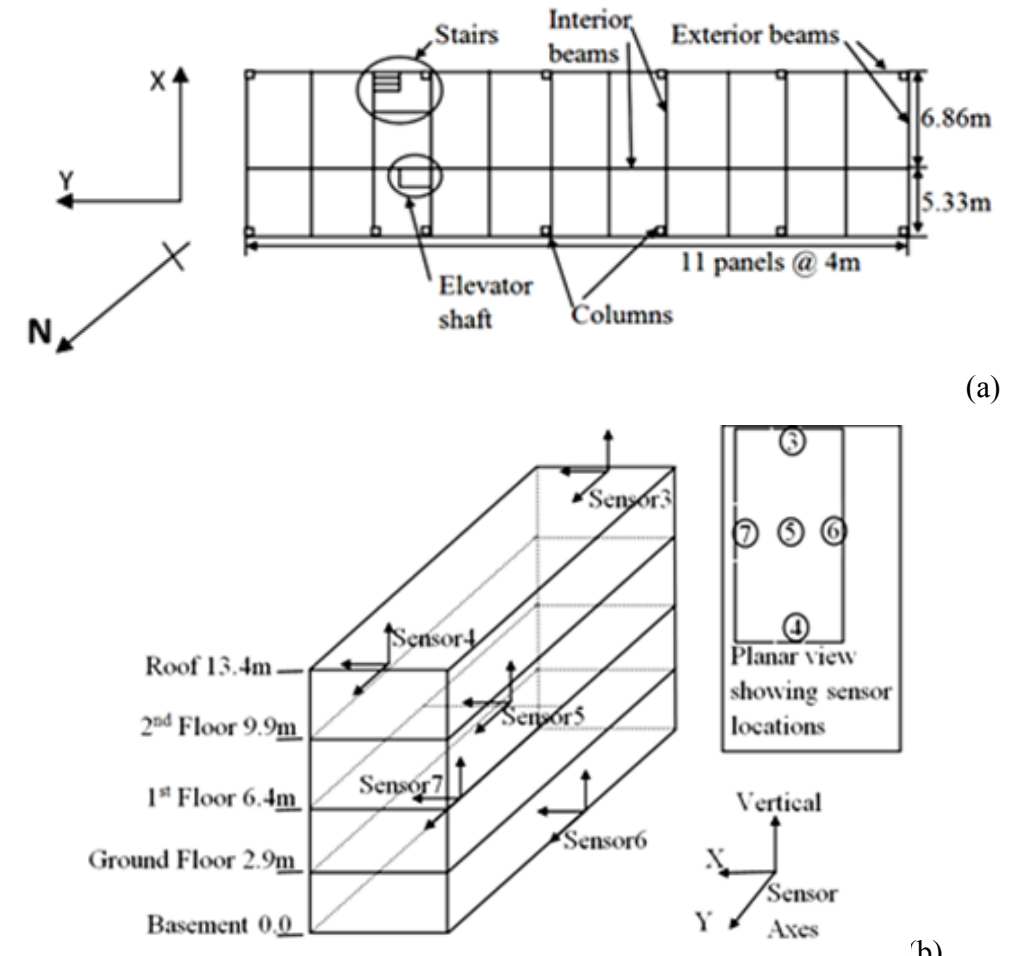

(a)

(b)

Figure 1. (a) Typical floor plan showing general dimensions and location of stairs and elevator shaft, and (b) Sensor array. 
Return to your MySPIE To Do List at http://myspie.org and approve or disapprove this submission. Your manuscript will not be published without this approval. Please contact author_help@spie.org with any questions or concerns.

\section{SYSTEM IDENTIFICATION FOR EVALUATING SSI EFFECTS}

In this section, the methodology of the N4SID system identification technique, its application to the instrumented building and the evaluation of SSI effects using this technique will be discussed.

\subsection{N4SID system identification technique}

This section provides a brief explanation of the N4SID system identification technique. Full details of the technique can be found in Van Overschee and De Moor ${ }^{8}$. After sampling of a continuous time state space model, the discrete time state space model can be written as:

$$
\begin{aligned}
& \boldsymbol{x}_{k+1}=\boldsymbol{A} \boldsymbol{x}_{k}+\boldsymbol{B} \boldsymbol{u}_{k}+\boldsymbol{w}_{k} \\
& \boldsymbol{y}_{k}=\boldsymbol{C} \boldsymbol{x}_{k}+\boldsymbol{D} \boldsymbol{u}_{k}+\boldsymbol{v}_{k}
\end{aligned}
$$

where $\boldsymbol{A}, \boldsymbol{B}, \boldsymbol{C}$ and $\boldsymbol{D}$ are the discrete time state, input, output and control matrices, respectively, whereas $\boldsymbol{x}_{k}$ and $\boldsymbol{y}_{k}$ are the state and output vectors and $\boldsymbol{u}_{k}$ is the excitation vector, respectively. Vectors $\boldsymbol{w}_{k}$ and $\boldsymbol{v}_{k}$ are the process and measurement noise, respectively, that are always present in real-life applications. In case of input/output system identification, data from both output $\boldsymbol{y}_{\boldsymbol{k}}$ and input $\boldsymbol{u}_{\boldsymbol{k}}$ are assembled in a block Hankel matrix, which is defined as a gathering of a family of matrices that are created by shifting the data matrices in time. After this, the identification involves two steps. The first step takes projections of certain subspaces calculated from input and output observations (in the block Hankel matrix) to estimate the state sequence of the system. This is usually achieved using singular value decomposition (SVD) and QR decomposition. In the second step, a least square problem is solved to estimate the system matrices $\boldsymbol{A}, \boldsymbol{B}, \boldsymbol{C}$ and $\boldsymbol{D}$. Then the modal parameters, i.e. natural frequencies, damping ratios and mode shapes, are found by eigenvalue decomposition of the system matrix $\boldsymbol{A}$.

\subsection{Application of N4SID technique to the instrumented building}

The N4SID technique derives state-space models for linear systems by applying the well-conditioned operations, like SVD, to the block Hankel data matrices. The analyst, however, has to determine a proper system order. The approach based on observing trends of the estimated modal parameters in the co-called stabilization charts (Figure 2) is often used: a range of system orders is tried and modal parameters which repeat themselves across that range are accepted as correct results. Stability tolerances are chosen based on the relative change in the modal properties, i.e. modal frequencies, damping ratios and mode shapes, of a given mode as the system order increases. For mode shapes stability, model assurance criterion (MAC) between the mode shapes of the present and previous orders was examined. MAC is an index that determines the similarity between two mode shapes. For modes $\boldsymbol{\phi}_{i}$ and $\boldsymbol{\phi}_{j}$, MAC is defined as':

$$
M A C=\frac{\left(\boldsymbol{\phi}_{i}^{T} \boldsymbol{\phi}_{j}\right)^{2}}{\left(\boldsymbol{\phi}_{i}^{T} \boldsymbol{\phi}_{i}\right)\left(\boldsymbol{\phi}_{j}^{T} \boldsymbol{\phi}_{j}\right)}
$$

In Equation (3), superscript $T$ denotes transpose.

\subsection{Evaluation of SSI effects}

For evaluation of SSI effects using system identification procedures, Stewart and Fenves ${ }^{10}$ proposed the following approach. Consider structure shown in Figure 3. The height $h$ is the vertical distance from the base to the roof (or another measurement point located on the building). The symbols denoting translational displacements are as follows: $u_{g}$ for the free field translational displacement, $u_{f}$ for the foundation translational displacement with respect to the free field, and $u$ for the roof translational displacement with respect to the foundation. Foundation rocking angle is denoted by $\theta$, and its contribution to the roof translational displacement is $h \theta$. The Laplace domain counterparts of these quantities will be denotes as $\hat{u}_{g}, \hat{u}_{f}, \hat{u}$ and $\hat{\theta}$, respectively.

Stewart and Fenves ${ }^{10}$ consider three different models and associated transfer functions $\left(H_{1}, H_{2}\right.$ and $\left.H_{3}\right)$ as follows:

$\bullet$

Flexible base model 
Return to your MySPIE To Do List at http://myspie.org and approve or disapprove this submission. Your manuscript will not be published without this approval. Please contact author_help@spie.org with any questions or concerns.

$$
H_{1}=\frac{\hat{u}_{g}+\hat{u}_{f}+\hat{u}+h \hat{\theta}}{\hat{u}_{g}}
$$

where input is the free field displacement $u_{g}$ and output is the total roof displacement $u_{g}+u_{f}+u+h \theta$.

- $\quad$ Pseudo flexible base model

$$
H_{2}=\frac{\hat{u}_{g}+\hat{u}_{f}+\hat{u}+h \hat{\theta}}{\hat{u}_{g}+\hat{u}_{f}}
$$

where input is the total foundation translational displacement $u_{g}+u_{f}$ and output is the total roof displacement $u_{g}+u_{f}+u+h \theta$.

- $\quad$ Fixed base model

$$
H_{3}=\frac{\hat{u}_{g}+\hat{u}_{f}+\hat{u}+h \hat{\theta}}{\hat{u}_{g}+\hat{u}_{f}+h \hat{\theta}}
$$

where input is the total foundation displacement including rocking $u_{g}+u_{f}+h \theta$ and output is the total roof displacement $u_{g}+u_{f}+u+h \theta$.

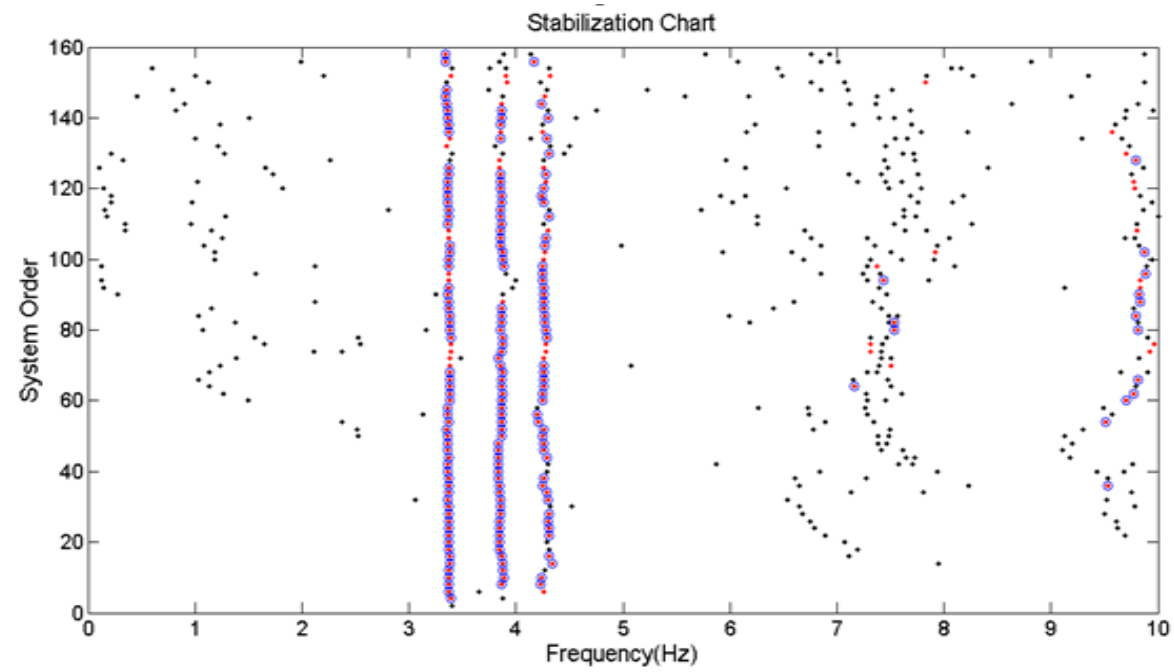

Figure 2. Typical stabilization chart showing stable modes.

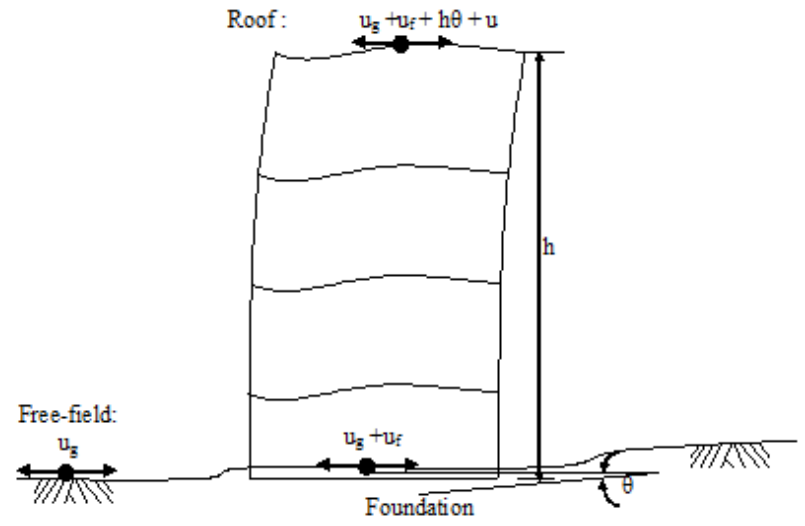

Figure 3. Inputs and outputs for evaluating SSI effects in system identification of buildings (Stewart \& Fenves 1998). 
Return to your MySPIE To Do List at http://myspie.org and approve or disapprove this submission. Your manuscript will not be published without this approval. Please contact author_help@spie.org with any questions or concerns.

In this study, we have considered only the flexible base model to ascertain the dynamic behavior (frequencies, damping ratios and mode shapes) of the building including SSI. Stewart and Fenves ${ }^{10}$ demonstrate that the poles of the flexible base transfer function $H_{l}$ give natural frequencies and damping ratios of the entire dynamical system comprising the structure, foundation and soil. In other words, the identified modal parameters are influenced by the translational and rotational stiffness and damping of soil. To provide a simple quantification of the effects of SSI on the response of the building in this study, modal vibration parameters were sought through N4SID technique for the flexible base case using input-output pairs consisting of a combination of free field, foundation and superstructure level recordings as explained in Equations (4). For the building under study, sensor 10 (the free field sensor) was considered as the input and sensors 3 , 4, 5, 6 and 7 as the outputs for the flexible base case.

\section{EVALUATION OF SEISMIC RESPONSE TRENDS INCLUDING SSI}

The objective of this part of research is to assess and understand the seismic response of building under a large number of earthquakes. In particular, trends are investigated between PRA and the identified first three natural frequencies and corresponding damping ratios of the building using 50 earthquakes. The presentation will thus follow selection of earthquakes, modal system identification, and correlating the PRAs with the identified frequencies and damping ratios for the flexible base model.

\subsection{Selection of earthquake records for the analyses}

For this study, 50 earthquakes recorded on the building which had epicenters within $200 \mathrm{~km}$ were selected. The reason for adopting this was to select earthquakes of such an intensity which can excite the modes of interest with acceptable signal-to-noise ratios providing quality system identification results. The area surrounding the buildings had not been hit by any strong earthquake since their instrumentation. The majority, i.e. 44 of the 50 recorded earthquakes, have a Richter magnitude ranging from 3 to 5 , except only six that have more than 5 , with 5.2 being the maximum value. This means that nearly all of the earthquakes fall into the category of low intensity except a very few that can be treated as moderate events.

Table 1 summarizes maximum accelerations recorded at the free field, base and roof sensors for the 50 earthquakes. The maximum PGA at the free field sensor 10 was recorded along Y-direction $(0.0138 \mathrm{~g})$ and was almost double the maximum along X-direction $(0.0074 \mathrm{~g})$. The maximum PGA at the base of the building was $0.0093 \mathrm{~g}$ and was captured by sensor 6 along Y-direction, and was a little higher than the maximum PGA recorded by sensor 7 along Y-direction $(0.0090 \mathrm{~g})$. Along the X-direction, sensor 7 recorded a slightly higher maximum PGA $(0.0061 \mathrm{~g})$ than sensor $6(0.0059 \mathrm{~g})$. The maximum PRA of the building in the Y-direction was $0.041 \mathrm{~g}$ captured by sensor 4 , which was double the maximum recorded acceleration in the X-direction of $0.021 \mathrm{~g}$. For sensor 3, the maximum PRA was almost the same $(0.040 \mathrm{~g})$ as that of sensor 4 along the Y-direction and almost double the maximum PRA acceleration in the X-direction $(0.019 \mathrm{~g})$. It should be noted, however, that the majority (94\%) of analyzed earthquakes resulted in PRAs below $0.015 \mathrm{~g}$ (this will also be seen clearly later in Figures 5 and 6).

Table 1. Maximum PGA and PRA recorded by individual sensors.

\begin{tabular}{|c|c|c|}
\hline Sensor & $\begin{array}{l}\text { Max. acceleration } \\
\text { in X-direction (g) }\end{array}$ & $\begin{array}{l}\text { Max. acceleration } \\
\text { in Y-direction (g) }\end{array}$ \\
\hline 10 (PGA) & 0.0074 & 0.0138 \\
\hline 6 (PGA) & 0.0059 & 0.0093 \\
\hline 7 (PGA) & 0.0061 & 0.0090 \\
\hline 3 (PRA) & 0.019 & 0.040 \\
\hline 4 (PRA) & 0.021 & 0.041 \\
\hline
\end{tabular}

\subsection{Modal identification of the instrumented building}

This subsection reports the results of the analysis using the same 50 earthquake records and performs system identification of modal parameters of the building. The identified natural frequencies and damping ratios are plotted against PRAs and their trends are statistically evaluated. N4SID technique was used to identify the first three frequencies, corresponding damping ratios and mode shapes. Sampling rate of the digitized signal was $200 \mathrm{~Hz}$ and for establishing stabilization charts system orders from 2 to 200 were considered. A typical stabilization chart is shown in Figure 2: the marker 'black dot' shows all the identified frequencies, 'red dot' shows stable frequencies and damping ratios, while 'blue circle' stable frequencies, damping ratios and mode shapes. In this research, an identified frequency was considered to be stable if the absolute deviation between the frequency identified at the present and previous order 
Return to your MySPIE To Do List at http://myspie.org and approve or disapprove this submission. Your manuscript will not be published without this approval. Please contact author_help@spie.org with any questions or concerns.

was less than or equal to $0.01 \mathrm{~Hz}$. A stable damping ratio was defined by an absolute deviation less than $5 \%$. For mode shapes stability, the MAC between the mode shapes of the present and previous order was to be at least $90 \%$ or greater. It can be seen in Figure 2 that three modes can be identified with confidence and subsequent discussions focus on these.

The typical first three mode shapes of the building for flexible base models are shown in Figure 4 in planar view. (Note that because of a limited number of measurement points those graphs assume the floors were rigid diaphragms.) The shape of the first mode shows it to be a translational mode along X-direction with some torsion. The second mode is nearly purely torsional, and the third one is translationally dominant along Y-direction coupled with torsion. Structural irregularities, such as those due to the internal longitudinal beams being not in the middle and the shear core present near the North end of the building, create unsymmetrical distribution of stiffness which has caused the modes to be coupled translational-torsional. Another plausible source of mode shape coupling is varying soil stiffness under different foundations and around different parts of the building.

During some events, the first, second or third mode or any two of them were missing in the system identification results, which suggests that during those particular events these modes did not vibrate strongly enough. In some events, the second and third modal frequencies tended to be very close and the minimum difference between these two was found to be $0.03 \mathrm{~Hz}$. This shows the capability of N4SID technique to identify very closely spaced modes.

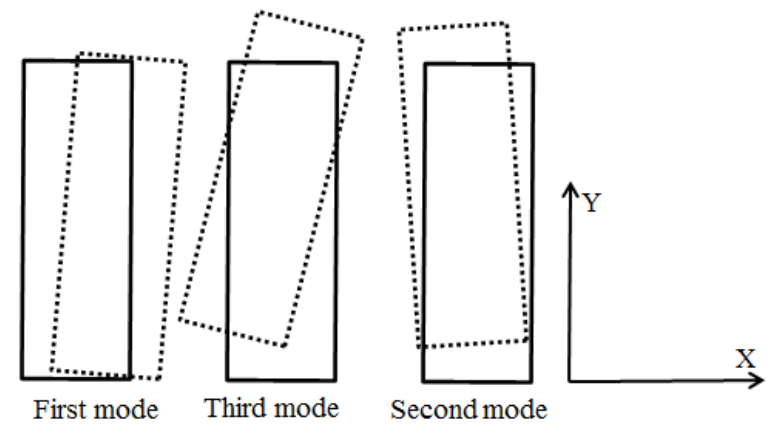

Figure 4. Planar views of the first three mode shapes of the building for flexible base model.

\subsection{Modal frequency dependence on PRA}

Table 2 shows the minimum, maximum, average and relative range (= (maximum-minimum)/average $\times 100 \%)$ values of the identified modal frequencies for the analyzed 50 earthquakes for the flexible base model. The average first three modal frequencies for the building are $3.33 \mathrm{~Hz}, 3.61 \mathrm{~Hz}$ and $3.79 \mathrm{~Hz}$ and the percentage changes in the first three frequencies are $14 \%, 19 \%$ and $11 \%$ respectively. It is of interest to explore whether, and if so how, those changes in frequencies correlate with response magnitude. Figures $5 \mathrm{a}$ and $\mathrm{b}$ show the results of modal frequency identification for the analyzed 50 earthquakes. The frequencies are plotted against PRAs in X-and Y-direction of a representative roof sensor (sensor 3). It can clearly be seen that modal frequencies decrease as the PRAs increase and this is observed for all three modes, and along both X- and Y-directions. In order to quantify relationships between PRAs and modal frequencies linear regression ${ }^{11}$ was applied. In Figures $5 \mathrm{a}$ and $\mathrm{b}$ the formulas relating the identified modal frequencies and PRA in both X-and Y-direction are listed. The negative values of the linear terms confirm again the decreasing trend of modal frequencies with increasing PRA. The strength of correlations of the variables is illustrated by $R^{2}$ or coefficient of determination ${ }^{12}$. In interpreting the $R^{2}$ coefficients, it was decided that $R^{2}>0.8$ denotes strong or good correlation, $R^{2}>0.5$ reasonable correlation, and $R^{2}>0.25$ weak but still perceivable correlation - those thresholds are not to be understood as 'hard'. The coefficients vary from 0.33 to 0.65 indicating that a linear relationship fits the data to a reasonable degree. Had more data with PRAs in the range beyond $0.01 \mathrm{~g}$ been available it would have helped to develop more refined relationship than the linear one.

\subsection{Modal damping ratio dependence on PRA}

Table 2 shows the minimum, maximum, average and relative range (= (maximum-minimum)/average $\times 100 \%)$ values of the identified modal damping ratios for the analyzed 50 earthquakes for flexible base model. The average values of damping ratios for the first, second and third modes are 3.4\%, 5.6\% and 3.1\%. It can be noticed that the identified damping ratios show considerable scatter for both buildings - the relative ranges were between $176 \%$ and $240 \%$. Figures 6a-f show the results of modal damping ratio identification for the analyzed 50 earthquakes. Like the modal frequencies previously, the damping ratios are plotted against PRAs in either X- or Y-direction of sensor 3. The initial observation 


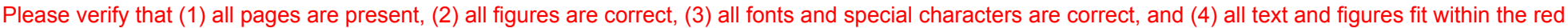
margin lines shown on this review document. Complete formatting information is available at http://SPIE.org/manuscripts

Return to your MySPIE To Do List at http://myspie.org and approve or disapprove this submission. Your manuscript will not be published without this approval. Please contact author_help@spie.org with any questions or concerns.

about considerable scatter of results, mentioned while analyzing Table 2, is now clearly revealed in the figures. No clear trends in damping ratios could be discerned.

Table 2. Summary of identified frequencies and damping ratios for flexible base model.

\begin{tabular}{|c|c|c|c|c|c|c|c|c|}
\hline \multirow[b]{2}{*}{ Mode } & \multicolumn{4}{|c|}{ Frequency (Hz) } & \multicolumn{4}{|c|}{ Damping ratios (\%) } \\
\hline & Min. & Max. & Avg. & $\begin{array}{l}\text { Relative } \\
\text { range }\end{array}$ & Min. & Max. & Avg. & $\begin{array}{l}\text { Relative } \\
\text { range }\end{array}$ \\
\hline $1^{\text {st }}$ & 3.02 & 3.50 & 3.33 & $14 \%$ & 1.2 & 7.3 & 3.4 & $176 \%$ \\
\hline $2^{\text {nd }}$ & 3.21 & 3.88 & 3.61 & $19 \%$ & 1.4 & 12.1 & 5.6 & $190 \%$ \\
\hline $3^{\text {rd }}$ & 3.48 & 3.90 & 3.79 & $11 \%$ & 1.0 & 8.3 & 3.1 & $240 \%$ \\
\hline
\end{tabular}

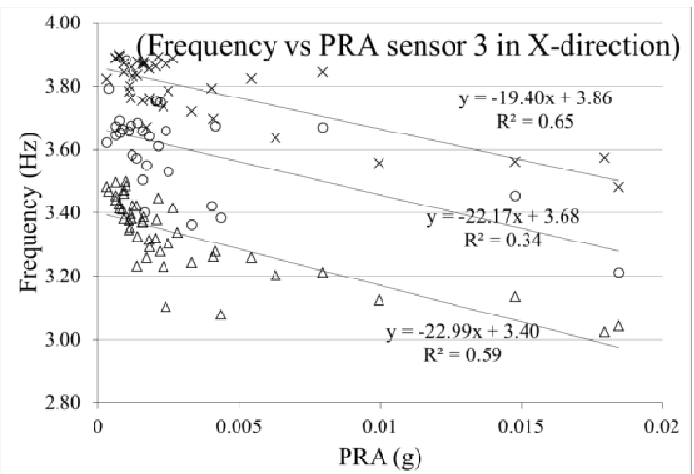

a)

1st freq. vs PRA $3 X$ 2nd Freq. vs PRA $3 X \times 3$ rd Freq. vs PRA $3 X$

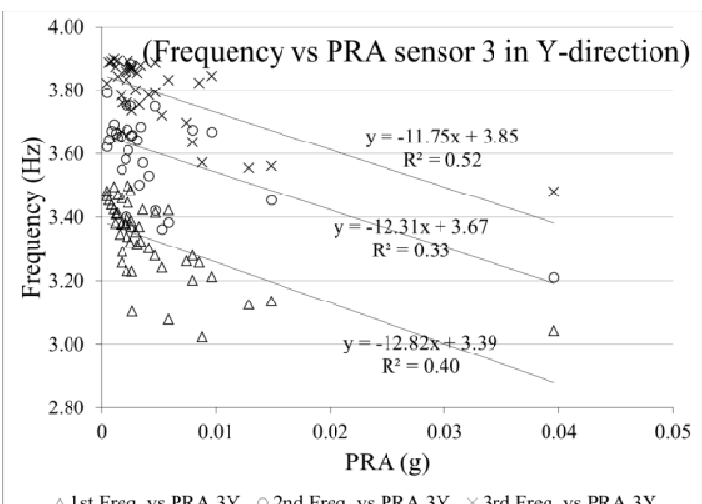

b)

$\triangle 1$ st Freq. vs PRA $3 Y \circ$ 2nd Freq. vs PRA $3 Y \times$ 3rd Freq. vs PRA $3 Y$

Figure 5. First three modal frequencies of the building for flexible base case vs. PRA of sensor 3: a) X-direction, and b)

Y-direction.

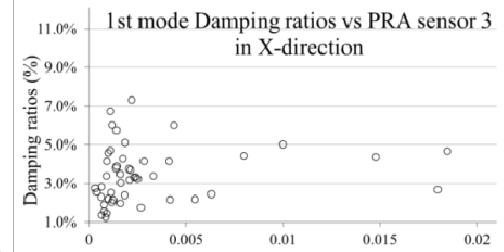

a)

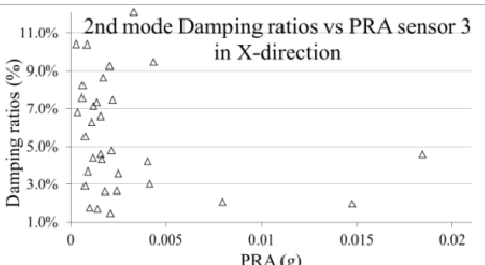

b)

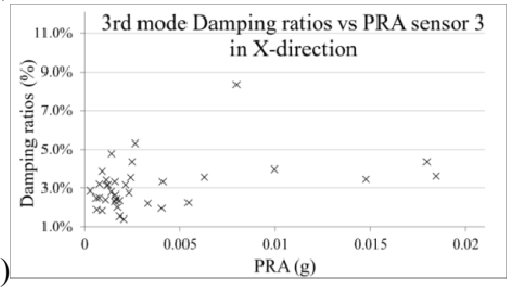

d)
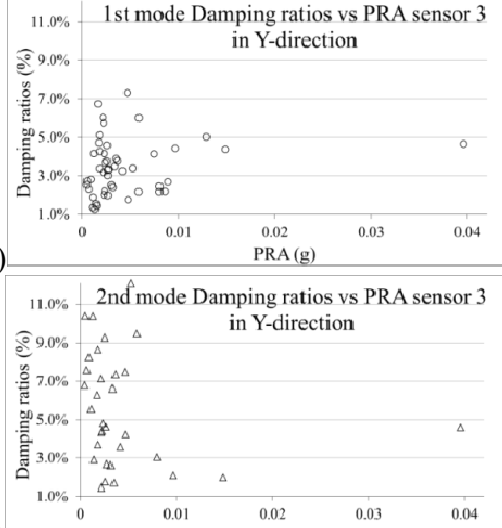

e)

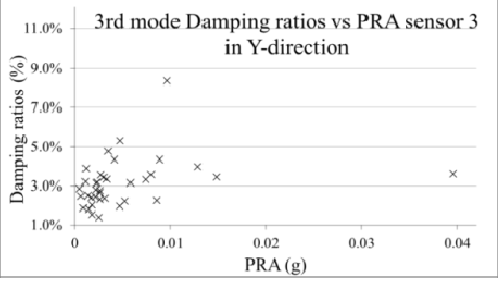

Figure 6. Modal damping ratios of the building for flexible base case: a) $1^{\text {st }}$ mode, b) $2^{\text {nd }}$ mode, c) $3^{\text {rd }}$ mode vs. Xdirection PRA of sensor 3; d) $1^{\text {st }}$ mode, e) $2^{\text {nd }}$ mode, and f) $3^{\text {rd }}$ mode vs. Y-direction PRA of sensor 3. 
Return to your MySPIE To Do List at http://myspie.org and approve or disapprove this submission. Your manuscript will not be published without this approval. Please contact author_help@spie.org with any questions or concerns.

\section{MODEL CALIBRATION USING SENSITIVITY BASED MODEL UPDATING}

This section describes briefly the methodology involved in model updating using a sensitivity based technique. Model updating is concerned with calibration of an FEM of a structure such that it can predict the measured responses of that structure. The sensitivity based model updating procedure generally comprises of three aspects: (i) selection of responses as reference data, (ii) selection of parameters to update, and (iii) an iterative model tuning. In sensitivity based updating, corrections/modifications are applied to the local physical parameters (geometric, material and boundary and connectivity conditions) of the FEM to modify it with respect to the reference (experimental) data which is in the form of measured modal frequencies and mode shapes. For parameter modification in FEM, the experimental responses are expressed as functions of analytical responses (from FEM), structural parameters and a sensitivity coefficient matrix. In terms of the first order Taylor series it can be expressed as:

$$
\boldsymbol{R}_{e}=\boldsymbol{R}_{a}+\boldsymbol{S}\left(\boldsymbol{P}_{u}-\boldsymbol{P}_{o}\right)
$$

or alternatively as:

$$
\Delta R=S \Delta P
$$

where $\boldsymbol{R}_{\boldsymbol{e}}$ and $\boldsymbol{R}_{\boldsymbol{a}}$ are the vectors of experimental and analytical response values, respectively, and $\boldsymbol{\Delta} \boldsymbol{R}$ is the difference between them, whereas $\boldsymbol{P}_{\boldsymbol{u}}$ and $\boldsymbol{P}_{\boldsymbol{o}}$ are vectors of updated and current parameters, respectively, and $\boldsymbol{\Delta} \boldsymbol{P}$ is the difference between them. $\boldsymbol{S}$ is the sensitivity matrix which can be calculated as:

$$
\boldsymbol{S}_{i j}=\frac{\partial \boldsymbol{R}_{a, i}}{\partial \boldsymbol{P}_{u, j}}
$$

Here $\boldsymbol{R}_{\boldsymbol{a}, \boldsymbol{i}}(\mathrm{i}=1, \ldots \ldots \ldots, \mathrm{n})$ and $\boldsymbol{P}_{\boldsymbol{u}, \boldsymbol{j}}(\mathrm{j}=1, \ldots \ldots \ldots, \mathrm{m})$ are the entries of the analytical structural response and the updating structural parameter vectors, respectively. Equation (9) calculates absolute sensitivities expressed in the units of the response and parameter values. For comparing relative sensitivities of different types of responses to relative changes in different parameters the relative normalized sensitivity matrix $\boldsymbol{S}_{\boldsymbol{n} r}$ can be calculated as ${ }^{13}$ :

$$
\boldsymbol{S}_{n r}=\boldsymbol{R}_{D, a}^{-1} \frac{\partial \boldsymbol{R}_{a, i}}{\partial \boldsymbol{P}_{u, j}} \boldsymbol{P}_{D, u}
$$

where $\boldsymbol{R}_{\boldsymbol{D}, \boldsymbol{a}}$ and $\boldsymbol{P}_{\boldsymbol{D}, \boldsymbol{u}}$ are square, diagonal matrices holding response and parameter values, respectively. Equation (8) can be determined, over-determined or under-determined depending on the number of responses $n$ being equal, larger or smaller than the number of parameters $m$, respectively. In all cases it can be solved, often in the least square sense, using a pseudo inverse:

$$
\Delta P=S^{+} \Delta R
$$

Here $\boldsymbol{S}^{+}$is the pseudo inverse of sensitivity matrix $\boldsymbol{S}$ which can be calculated for the three different cases as follows ${ }^{14}$ :

$$
\boldsymbol{S}^{+}= \begin{cases}\boldsymbol{S}^{-1} & \text { for } n=m, \\ \left(\boldsymbol{S}^{T} \boldsymbol{S}\right)^{-1} \boldsymbol{S}^{T} & \text { for } n>m, \\ \boldsymbol{S}^{T}\left(\boldsymbol{S} \boldsymbol{S}^{T}\right)^{-1} & \text { for } n<m,\end{cases}
$$

One advantage of the sensitivity based model updating is the direct pairing of measurement points in the test with the $\mathrm{FEM}^{15}$. Correlation analysis comprises of studying the relative difference in frequencies and modal shapes of the analytical and experimental responses. Target parameters $\boldsymbol{R}_{\boldsymbol{e}}$ (experimental response values) are usually the natural frequencies and mode shapes measured from the real structure, whereas updating parameters $\boldsymbol{P}_{\boldsymbol{o}}$ (initial iterative parameters) are uncertain parameters modeled in FEM which can include geometric and material properties or boundary and connectivity conditions. The important issues regarding the parameter selection are the number of parameters to be updated and preference of certain parameters among many candidates because they are influential based on the sensitivity analysis ${ }^{14}$. Also, the selected parameters should be uncertain and expected to vary, otherwise blindly updated 
Return to your MySPIE To Do List at http://myspie.org and approve or disapprove this submission. Your manuscript will not be published without this approval. Please contact author_help@spie.org with any questions or concerns.

parameters will result in physically meaningless results. One way to avoid such situation is to apply upper and lower bounds to the updating parameters. If there are a number of candidate parameters available for updating then a good way to start is to perform sensitivity analysis for all and compute relative sensitivities (Equation (11)) and retain only those that are influential. This is also necessary to avoid ill-conditioning of the sensitivity matrix $\boldsymbol{S}^{16}$. When the results of the FEM and target values are within desired range (convergence criterion) the iteration stops.

\section{DEVELOPING AND UPDATING FEM OF INSTRUMENTED BUILDING INCLUDING SSI}

This section describes the development of an FEM and application of the sensitivity base model updating technique considering SSI. A three dimensional FEM of the instrumented building was developed in the FEMtools software ${ }^{18}$ using the available structural drawings and at-site measurements. Beams and columns were modeled as two nodes LINE2 elements, and slabs, stairs, shear core, cladding and roof steel sheeting as four node QUAD4 elements. The density and modulus of elasticity of concrete for all the elements were taken as $2400 \mathrm{~kg} / \mathrm{m}^{3}$ and $30 \mathrm{GPa}$, respectively. The steel density and modulus of elasticity were taken as $7800 \mathrm{~kg} / \mathrm{m}^{3}$ and $200 \mathrm{GPa}$, respectively. The steel trusses present at the roof level were modeled as equivalent steel beams. The masses of the timber purlins, planks and corrugated steel sheets were calculated and lumped at the equivalent steel beams. All the dead and superimposed loads were applied as area loads or line loads at their respective positions.

Since the structure under study is an office building, there are a large number of partition walls present. The stiffness values of gypsum wall partitions were taken from Kanvinde and Deierlein ${ }^{17}$ as $2800 \mathrm{kN} / \mathrm{m}$ and were modeled as twonode spring elements along the diagonal directions. The mass due to partition walls, false ceilings, attachments, furniture and live loads were collectively applied at the floor slabs as area mass of $450 \mathrm{~kg} / \mathrm{m}^{2}$. External cladding in the building is made up of fiberglass panels with insulating material on the inner side. The density and modulus of elasticity values of fiberglass were taken as $1750 \mathrm{~kg} / \mathrm{m}^{3}$ and $10 \mathrm{GPa}$, respectively, from literature ${ }^{19}$ and their mass was calculated manually $(100 \mathrm{~kg} / \mathrm{m})$ and applied at the perimeter beams.

Soil-structure-interaction at the base is idealized as six DOFs springs consisting three translations and rotations. The partial submersion of the building is idealized as springs at mid height of the basement columns. For the column springs along the longitudinal and lateral directions one translation DOF only i.e. stiffness and damping coefficients along X and $\mathrm{Y}$ direction, respectively, were taken into account, while for the corner column springs both $\mathrm{X}$ and $\mathrm{Y}$ translation stiffness and damping coefficients were considered. The values of spring stiffness and damping coefficients were calculated using the procedure explained in Gazetas ${ }^{20}$. Soil present at the site is classified according to the New Zealand Standard NZS1 $170^{21}$ as class D (deep or soft soil). No other information is available regarding the type of soil. The shear wave velocity was taken as $160 \mathrm{~m} / \mathrm{s}$ and the correspondingly dynamic shear modulus as $47 \mathrm{GPa}$ considering the limitations of soil class D. Since the building is partially submerged in soil, the equivalent soil springs for this situation are calculated using the submerged column as a footing using $\operatorname{Gazetas}^{20}$. Figure 7 shows the three dimensional FEM having structural and non- structural elements (cladding, partition walls, and stairs) and soil flexibility modeled.

For this study, FEM results are compared and calibrated with the dynamic properties of the flexible base model identified during the largest recorded earthquake of October 10th, 2009, which had the epicenter 20km North-West of Wellington, Richter magnitude of 4.8, PGA at the free field and base of $0.014 \mathrm{~g}$ and $0.009 \mathrm{~g}$, respectively, and PRA of $0.0412 \mathrm{~g}$. The following discussion will include the updating of FEM comprising of correlation analysis, selection of response and updating parameters, and finally updated results.

\subsection{Correlation analysis}

The pairing of FEM nodes and measurement points (green points) is shown in Figure 7. The correlation of dynamic properties of the FEM and measured responses is summarized in Table 3. Table 3 shows that the difference between the initial FEM and measured frequencies are under $7 \%$ for all three modes. The correlation of mode shapes expressed by MAC values is very good for the second mode, while for the first and third modes MAC values are satisfactory. The MAC matrix illustrating orthogonality conditions between all combinations of the initial FEM and measured mode shapes is shown in Figure 8a. Two types of correlation coefficients namely absolute relative difference (CCABS) between frequencies and average MAC values (MACMEAN) are considered for the correlation analysis and are given by:

$$
C C A B S=\frac{1}{n} \sum_{i=1}^{n} C_{r_{i}} \frac{\left|\Delta f_{i}\right|}{f_{i}}
$$


Return to your MySPIE To Do List at http://myspie.org and approve or disapprove this submission. Your manuscript will not be published without this approval. Please contact author_help@spie.org with any questions or concerns.

$$
\text { MACMEAN }=1-\frac{1}{n} \sum_{i=1}^{n} C_{r_{i}} M A C_{i}
$$

Here $n$ is the total number of response frequencies or mode shapes considered, $C_{r_{i}}$ is the relative weighting on the response error value, $\Delta f_{i}$ and $f_{i}$ are the difference in the FEM and measured frequency, respectively.

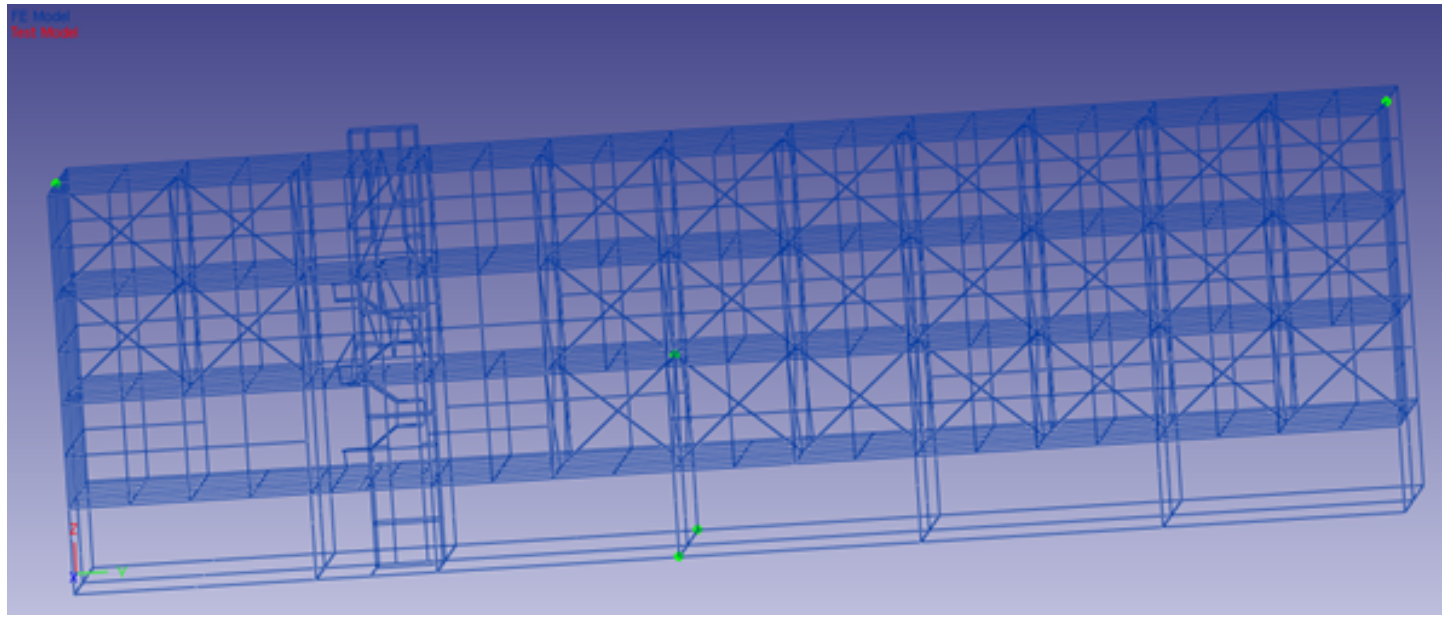

Figure 7. Three dimensional FEM of the building showing stairs, shear core and partition walls. (Cladding has been removed from the view to show the inner details. Green points show FEM nodes and measurement points pairing.)

Table 3. Correlation between initial and updated FEM and measured responses.

\begin{tabular}{|c|c|c|c|c|c|c|c|c|}
\hline \multicolumn{3}{|c|}{ FEM } & \multicolumn{2}{|c|}{$\begin{array}{l}\text { Measured } \\
\text { response }\end{array}$} & \multirow{2}{*}{$\begin{array}{l}\text { Diff. b/w } \\
\text { initial FEM } \\
\text { and } \\
\text { measured } \\
\text { freq. }(\%)\end{array}$} & \multirow{2}{*}{$\begin{array}{l}\text { Diff. b/w } \\
\text { updated } \\
\text { FEM and } \\
\text { measured } \\
\text { freq. }(\%)\end{array}$} & \multirow{2}{*}{$\begin{array}{l}\text { Initial } \\
\text { MAC } \\
\text { (\%) }\end{array}$} & \multirow{2}{*}{$\begin{array}{l}\text { Updated } \\
\text { MAC } \\
(\%)\end{array}$} \\
\hline Mode & $\begin{array}{l}\text { Initial freq. } \\
(\mathrm{Hz})\end{array}$ & $\begin{array}{l}\text { Updated } \\
\text { freq. }(\mathrm{Hz})\end{array}$ & Mode & $\begin{array}{l}\text { Freq. } \\
(\mathrm{Hz})\end{array}$ & & & & \\
\hline 1 & 2.91 & 3.02 & 1 & 3.04 & -4.34 & -0.56 & 78 & 80 \\
\hline 2 & 3.43 & 3.20 & 2 & 3.21 & 6.71 & -0.29 & 92 & 96 \\
\hline 3 & 3.71 & 3.51 & 3 & 3.48 & 6.65 & 0.73 & 63 & 78 \\
\hline
\end{tabular}

\subsection{Sensitivity analysis and selection of response and updating parameters}

The response/target parameters include the three measured frequencies and MAC values. Sensitivity analysis was performed to ascertain the most suitable parameters for updating the FEM also keeping in mind the uncertainty of the selected parameters. This is also required to produce a genuine improvement in the FEM. Three parameters, namely: (i) stiffness of soil springs for columns, perimeter and inner foundations, modulus of elasticity of (ii) modulus of elasticity of all concrete members, and (iii) modulus of elasticity of cladding are selected. To avoid physically meaningless results, upper and lower bounds were applied to the updating parameters depending on their perceived uncertainty as shown in Table 4.

\subsection{Updating results and discussion}

Table 3 shows the correlation values after updating. All the FEM frequencies are in good agreement with the measured values with the largest error not exceeding $0.8 \%$. The MAC values have also improved slightly for the first and second mode and are equal to or are above $80 \%$, while for the third mode shape it has improved considerably but is still below $80 \%$. The updated MAC matrix is shown in Figure 8b. The correlation coefficient CCABS has improved from 5.9 to 0.53 (Table 3), while MACMEAN has improved from 22.3 
Return to your MySPIE To Do List at http://myspie.org and approve or disapprove this submission. Your manuscript will not be published without this approval. Please contact author_help@spie.org with any questions or concerns.
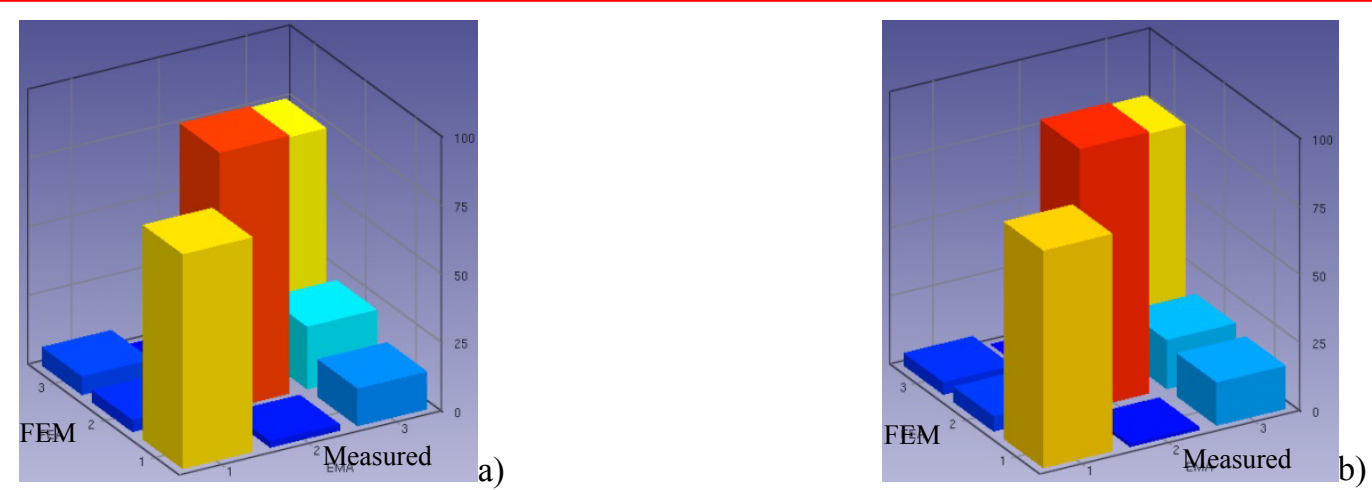

Figure 8. MAC matrix between FEM and measured mode shapes: (a) initial FEM (b) updated FEM.

Table 4. Changes in updating parameters.

\begin{tabular}{|c|c|c|c|c|c|c|}
\hline No. & Type & Detail & Initial value & $\begin{array}{l}\text { Upper and } \\
\text { lower bounds }\end{array}$ & Updated value & $\begin{array}{l}\text { Percent } \\
\text { change }\end{array}$ \\
\hline 1 & Stiffness & $\begin{array}{l}\text { Soil springs for } \\
\text { foundations at the base } \\
\text { and at column levels }\end{array}$ & Variable & \pm 50 & Variable & $4 \%$ \\
\hline 2 & Modulus & Cladding & $10 \times 10^{9} \mathrm{~N} / \mathrm{m}^{2}$ & \pm 40 & $7.2 \times 10^{9} \mathrm{~N} / \mathrm{m}^{2}$ & $-28 \%$ \\
\hline 4 & $\begin{array}{l}\text { of } \\
\text { elasticity }\end{array}$ & All concrete members & $3.0 \times 10^{10} \mathrm{~N} / \mathrm{m}^{2}$ & \pm 25 & $3.6 \times 10^{10} \mathrm{~N} / \mathrm{m}^{2}$ & $20 \%$ \\
\hline
\end{tabular}

to 15.3. Table 4 shows the changes in the values of the selected updating parameters. The maximum change was for the cladding stiffness which decreased by $28 \%$ from the initially assumed value. This illustrates that cladding stiffness was overestimated in the beginning. For the modulus of elasticity of reinforced concrete the increase is by $20 \%$. This change represents change in all the reinforced concrete members of the building. The initial estimate of modulus of elasticity of reinforced concrete was based on the normal concrete without any reinforcement value $(25 \mathrm{GPa})$ with a $20 \%$ increase to take into account the reinforcement (30GPa). The updated value shows that almost $44 \%$ increase was required in this case to calibrate the response of the FEM to the measured values. The values for the modulus of elasticity for reinforced concrete members and cladding were taken from literature and might not represent the actual values, therefore large changes can be expected. However, the change in the soil springs stiffness after updating are only $4 \%$ which is not significant. The changes in the updating parameters represented the global changes of stiffness leading to the global changes of dynamic properties of the structure.

\section{CONCLUSIONS}

This study comprises of two parts. The first part involves the evaluation of seismic response trends of an RC building using state-of-the-art N4SID system identification technique. The frequencies showed a clear decreasing trend with increasing PRA, and their linear correlations were found to be of a reasonable degree. The damping ratios had scattered values with no clear trend. The second part involves developing an FEM including SSI and NSCs and updating it using a sensitivity based model updating technique. The updating parameters included a structural parameter (stiffness of concrete), a non-structural parameter (stiffness of cladding), and soil stiffness. The match between the frequencies after updating was found to be very good, while MAC values were good to reasonable after updating.

\section{ACKNOWLEDGEMENTS}

Grateful acknowledgement is due to GeoNet staff for facilitating this research. Particular thanks go to Dr Jim Cousins, Dr S.R. Uma and Dr Ken Gledhill. The first author would also like to thank Higher Education Commission (HEC) Pakistan for funding his $\mathrm{PhD}$ study. 
Return to your MySPIE To Do List at http://myspie.org and approve or disapprove this submission. Your manuscript will not be published without this approval. Please contact author_help@spie.org with any questions or concerns.

\section{REFERENCES}

[1] Celebi, M., "Recorded earthquake responses from the integrated seismic monitoring network of the Atwood Building, Anchorage, Alaska," Earthquake Spectra 22(4), 847-864 (2006).

[2] Satake, N., and Yokota, H., "Evaluation of vibration properties of high-rise steel buildings using data of vibration tests and earthquake observations," Journal of Wind Engineering and Industrial Aerodynamics 59(23), 265-282 (1996).

[3] Trifunac, M. D., Ivanovic, S. S., and Todorovska, M. I., "Apparent periods of a building. I: Fourier analysis," Journal of Structural Engineering ASCE 127(5), 517-526 (2001).

[4] Brownjohn, J. M. W., and Xia, P. Q., "Dynamic assessment of curved cable-stayed bridge by model updating," Journal of Structural Engineering ASCE 126(2), 252-260 (2000).

[5] Farrar, C. R., Sohn, H., and Doebling, S. W., "Structural health monitoring at Los Alamos National Laboratory," US-Korea Conference on Science and Technology, Entrepreneurship and Leadership, Chicago, Illinois, 1-11 (2000).

[6] Trifunac, M. D., and Todorovska, M. I., "Recording and interpreting earthquake response of full-scale structures," Proc. NATO Advanced Research Workshop on Strong-Motion Instrumentation for Civil Engineering Structures, Kluwer Academic Publications 131-155 (1999).

[7] Van Overschee, P., and De Moor, B., "N4SID: Subspace algorithms for the identification of combined deterministic-stochastic systems," Automatica 30(1), 75-93 (1994).

[8] Van Overschee, P., and De Moor, B., Subspace identification for linear systems, Kluwer Academic Publishers, Dordrecht, Netherlands (1996).

[9] Ewins, D. J., Modal testing: Theory, practice and application, Research Studies Press, Baldock, Hertfordshire, UK (2000).

[10] Stewart, J. P., and Fenves, G. L., "System identification for evaluating soil-structure interaction effects in buildings from strong motion recordings," Earthquake Engineering and Structural Dynamics 27(8), 869-885 (1998).

[11] Montgomery, D., Peck, E. A. and Vining, G., Introduction to linear regression analysis, Wiley, New York (2001).

[12] Steel, R. and Torrie, J., Principles and procedures of statistics, McGraw-Hill, New York (1960).

[13] Brownjohn J. M. W., Moyo P., Omenzetter P., Lu Y., "Assessment of highway bridge upgrading by dynamic testing and finite element model updating," Journal of Bridge Engineering, ASCE 8(3), 162-172 (2003).

[14] Brownjohn, J. M. W., Xia, P.-Q., Hao, H., and Xia, Y., "Civil structure condition assessment by FE model updating: methodology and case studies," Finite Elements in Analysis and Design 37, 761-775 (2001).

[15] Zhao, X., Sun, H. H., and Zheng, Y. M., "Identification and updating for the three-dimensional finite element model of a long span steel skybridge," Structural Design of Tall and Special Buildings 18(6), 625-646 (2009).

[16] Brownjohn, J. M. W., Hong, H., and Chien, P. T., "Assessment of structural condition of bridges by dynamic measurements," Report No. RG 5/97, Nanyang Technological University Singapore (2001).

[17] Dynamic Design Solutions, FEMtools for Windows, Dynamic Design Solutions, Leuven, Belgium (2001).

[18] Kanvinde, A. M., and Deierlein, G. G., "Analytical models for the seismic performance of gypsum drywall partitions," Earthquake Spectra 22(2), 391-411 (2006).

[19] Gaylord, M. W., Reinforced plastics: Theory and practice, 2nd Edition, Cahners Publishing Co., New York (1974).

[20] Gazetas, G., "Formulas and charts for impedances of surface and embedded foundations," Journal of Geotechnical Engineering, ASCE 117(9), 1363-1381 (1991).

[21] Standards New Zealand, Structural design actions. Part 5: Earthquake actions - New Zealand, Standards New Zealand, Wellington, New Zealand (2004). 